\title{
Inhibitory Effects of Glycyrrhetinic Acid on the Delayed Rectifier Potassium Current in Guinea Pig Ventricular Myocytes and HERG Channel
}

\author{
Delin Wu, ${ }^{1}$ Linqing Jiang, ${ }^{1}$ Hongjin Wu, ${ }^{1}$ Shengqi Wang, ${ }^{2}$ Sidao Zheng, ${ }^{1}$ Jiyuan Yang, \\ Yuna Liu, ${ }^{1}$ Jianxun Ren, ${ }^{1}$ and Xianbing Chen ${ }^{1}$
}

${ }^{1}$ Beijing Hospital of Integrated Traditional Chinese and Western Medicine, Beijing 100039, China

${ }^{2}$ Beijing Institute of Radiation Medicine, Beijing 100850, China

Correspondence should be addressed to Hongjin Wu; whjyuanzhang@yahoo.com.cn

Received 19 March 2013; Revised 7 July 2013; Accepted 11 July 2013

Academic Editor: Hao Xu

Copyright (c) 2013 Delin Wu et al. This is an open access article distributed under the Creative Commons Attribution License, which permits unrestricted use, distribution, and reproduction in any medium, provided the original work is properly cited.

Background. Licorice has long been used to treat many ailments including cardiovascular disorders in China. Recent studies have shown that the cardiac actions of licorice can be attributed to its active component, glycyrrhetinic acid (GA). However, the mechanism of action remains poorly understood. Aim. The effects of GA on the delayed rectifier potassium current $\left(I_{\mathrm{K}}\right)$, the rapidly activating $\left(I_{\mathrm{Kr}}\right)$ and slowly activating $\left(I_{\mathrm{Ks}}\right)$ components of $I_{\mathrm{K}}$, and the HERG $\mathrm{K}^{+}$channel expressed in HEK-293 cells were investigated. Materials and Methods. Single ventricular myocytes were isolated from guinea pig myocardium using enzymolysis. The wild type HERG gene was stably expressed in HEK293 cells. Whole-cell patch clamping was used to record $I_{\mathrm{K}}\left(I_{\mathrm{Kr}}, I_{\mathrm{Ks}}\right)$ and the HERG K ${ }^{+}$current. Results. GA $(1,5$, and $10 \mu \mathrm{M})$ inhibited $I_{\mathrm{K}}\left(I_{\mathrm{Kr}}, I_{\mathrm{Ks}}\right)$ and the HERG $\mathrm{K}^{+}$current in a concentration-dependent manner. Conclusion. GA significantly inhibited the potassium currents in a dose- and voltage-dependent manner, suggesting that it exerts its antiarrhythmic action through the prolongation of APD and ERP owing to the inhibition of $I_{\mathrm{K}}\left(I_{\mathrm{Kr}}, I_{\mathrm{Ks}}\right)$ and $\mathrm{HERG} \mathrm{K}^{+}$ channel.

\section{Introduction}

Cardiac arrhythmias are associated with significant morbidity and mortality in developed and developing countries. Although nonpharmacologic approaches, ablative therapy, and implantable defibrillators, for example, are being used more and more commonly as complementary and alternative interventions for the treatment of cardiac arrhythmias, drug therapy was traditionally the mainstay of arrhythmia treatment. Improved understanding of the cardiomyocyte ion channels holds the promise of identifying novel targets for the treatment of cardiac arrhythmias. Furthermore, the limited efficacy and the potency of provoking life-threatening arrhythmias of present drugs have generated interest in finding new antiarrhythmic agents [1].

Potassium channels constitute the most abundant family of ion channels involved in cardiac physiological or pathophysiological processes, disruptions of which could give rise to prolongation of the action potential and potentiate occurrence of lethal arrhythmias subsequently $[2,3]$. In the hearts of many mammalian species including humans, delayed rectifier $\mathrm{K}^{+}$current $\left(I_{\mathrm{K}}\right)$, the major outward potassium current responsible for ventricular repolarization, can be divided into at least two different components, rapidly activating $\left(I_{\mathrm{Kr}}\right)$ and slowly activating $\left(I_{\mathrm{Ks}}\right)$. The human etherà-go-go-related gene (HERG) encodes the $\alpha$-subunit for the rapid delayed rectifier potassium channel $\left(I_{\mathrm{Kr}}\right)$ in cardiac myocytes. $I_{\mathrm{Kr}}$ and $I_{\mathrm{Ks}}$ are pivotal in cardiac repolarization, especially in the later phases of the action potential $[4,5]$. Although the structural and functional aspects of potassium channels have been widely examined, only a few $\mathrm{K}^{+}$channel modulators are being used clinically at present for the unwanted adverse effects $[2,6]$. As an alternative to find new antiarrhythmic agents, there has been increased interest in investing natural compounds that are effective against cardiac arrhythmia. 
Glycyrrhiza radix is a commonly prescribed herb to prevent palpitations in Chinese traditional medicine for about 2000 years, derived from the dried roots and rhizomes of Glycyrrhiza uralensis, G. glabra, and G. inflata. Glycyrrhizin, the major constituent of G. glabra, is a glycoside, which occurs as an admixture of sodium, potassium and calcium salts [7]. Orally administered, glycyrrhizin is poorly absorbed by the intestinal tract and is hydrolyzed by $\beta$-D-glucuronidasecontaining intestinal bacteria to yield two molecules of $\mathrm{D}$ glucuronic acid and the aglycone glycyrrhetinic acid (GA), a pentacyclic triterpene [8]. If intravenously administered, GA is metabolized in the liver by lysosomal $\beta$-D-glucuronidase to the 3-monoglucuronide of glycyrrhetinic acid. This metabolite is excreted via the bile into the intestine, where it is transformed by bacteria into GA, which can be reabsorbed, causing a pronounced delay in terminal plasma clearance [9].

The use of Glycyrrhiza uralensis as a pharmacological remedy dates back far into the past [10]. Various pharmacological properties of licorice have been proved including cardioprotective [11, 12], antiulcer, anti-inflammatory, spasmolytic, antioxidative, contravariant, antiviral, anticancer, and hepatoprotective effects, as well as eliminating phlegm and reinforcing memory [7, 13-15]. Many components have been isolated from licorice including triterpene saponins, flavonoids, isoflavonoids, and chalcones. Triterpene saponins are the main components of Glycyrrhiza radix and its pharmacological activities are comparatively well understood and clear.

Recently, wide-ranging studies have provided evidence that GA is cardioprotective; this action involves different pathways. In rat cardiac mitochondria [16], GA was shown to increase permeability and concomitant release of proapoptotic factors. In particular, GA, acting as a gap junction inhibitor, influences connexin 43 , the major gap junctionforming protein in adult cardiac ventricles and a regulator of mitochondrial function [17]. Studies have demonstrated that GA and its derivatives affect the inotropic, lusitropic, chronotropic, and coronary performances of the mammalian heart and the signal transduction pathways that could be involved [9]. Furthermore, research has demonstrated that GA reduces cardiac sodium currents [18], particularly the late $I_{\mathrm{Na}}$. These findings might help to elucidate the traditional use of licorice in therapy for cardiovascular disorders [19]. It has also been reported that $18 \beta-$-GA has significant potential for development as a novel antiarrhythmic agent and for treating myocardial ischemia by preferentially blocking the $I_{\mathrm{Na}, \mathrm{L}}[20]$. However, the effects of GA on the potassium channel, especially the rapid and slow components of the delayed rectifier potassium current, are not clearly defined.

In this study, we investigated the effects of GA on the $I_{\mathrm{K}}\left(I_{\mathrm{Kr}}, I_{\mathrm{Ks}}\right)$ in guinea pig ventricular myocytes. We also extended our study to investigate the effects of GA on the human ether-à-go-go-related gene (HERG) $\mathrm{K}^{+}$channel current expressed in HEK-293 cells. Our study could provide theoretical support for developing the significant potential of GA as a novel antiarrhythmic agent.

\section{Materials and Methods}

2.1. Materials. Glycyrrhetinic acid ((GA) molecular weight 470.6, purity > 99\%) was obtained from the Chinese Biological Product Assay Institute (Beijing, China). The white powder was dissolved in dimethylsulfoxide (DMSO) as stock. The percentage of DMSO in the final solution was less than $0.1 \%$. Collagenase II was obtained from Worthington Biochemical Corporation (Lakewood, NJ, USA). Protease XIV, $\mathrm{Na}_{2}$ ATP, MgATP, $\mathrm{CdCl}_{2}$, L-Glutamic acid, Taurine, and EGTA were purchased from Sigma Co. Other reagents were of analytical reagent grade. Male guinea pigs weighing 300$350 \mathrm{~g}$ were provided by the Vital river Company, Certificate no.: SCXK (Jing) 2006-0009.

2.2. Solutions. $\mathrm{Ca}^{2+}$-free Tyrode's solution $(\mathrm{mM})$ contained $\mathrm{NaCl}$ 137, $\mathrm{KCl}$ 5.4, $\mathrm{NaH}_{2} \mathrm{PO} 41.2, \mathrm{MgCl}_{2}$ 1.2, HEPES 10, glucose 10, and Taurine 10 (adjusted to $\mathrm{pH}$ 7.36-7.38 with $\mathrm{NaOH})$.

Kraft-Brühe (KB) solution (mM) contained L-glutamic acid 50, $\mathrm{KCl} 40, \mathrm{KH}_{2} \mathrm{PO} 420$, Taurine $20, \mathrm{MgCl}_{2} 3.0, \mathrm{KOH}$ 70, EGTA 0.5, HEPES 10, and glucose 10 (adjusted to pH 7.25 with $\mathrm{KOH})$.

For $I_{\mathrm{K}}\left(I_{\mathrm{Kr}}, I_{\mathrm{Ks}}\right)$ recordings from ventricular myocytes, the control bath solution contained $(\mathrm{mM}) \mathrm{NaCl} 135, \mathrm{KCl} 5.4$, $\mathrm{CaCl}_{2} 1.0, \mathrm{CdCl}_{2}$ 0.2, $\mathrm{NaH}_{2} \mathrm{PO} 40.33, \mathrm{MgCl}_{2} 1.0$, HEPES 5, and glucose 5 (adjusted to $\mathrm{pH}$ 7.36-7.38 with $\mathrm{NaOH}$ ). Drugs were added to the bath solution. Pipettes had tip resistances of 1.5-2 $\mathrm{M} \Omega$ when filled with a solution containing $(\mathrm{mM}) \mathrm{KCl}$ $140, \mathrm{MgCl}_{2}$ 1, HEPES 5, EGTA 10, and $\mathrm{Na}_{2}$ ATP 2 (adjusted to pH 7.25 with $\mathrm{KOH})$.

To record HERG activity in the HEK 293 cells, the internal solution contained (mM) $\mathrm{KCl} 130, \mathrm{MgCl}_{2}$ 1, HEPES 10, EGTA 10, and MgATP 5 (adjusted to $\mathrm{pH} 7.25$ with $\mathrm{KOH}$ ). The external solution contained (mM) $\mathrm{NaCl} 136, \mathrm{KCl} 5.4, \mathrm{CaCl}_{2} 1$, $\mathrm{MgCl}_{2}$ 1, HEPES 10, and glucose 10 (adjusted to $\mathrm{pH}$ 7.36-7.38 with $\mathrm{NaOH}$ ).

2.3. Isolation of Single Ventricular Myocytes. Adult guinea pigs were fully anesthetized by intraperitoneal injection of urethane $(40 \mathrm{mg} / \mathrm{kg})$. The hearts were quickly removed and mounted on a Langendorff column, and cardiac myocytes were isolated as follows. The heart was dissected and rinsed in cold oxygenated $\mathrm{Ca}^{2+}$-free Tyrode's solution and then perfused in the Langendorff apparatus at $37^{\circ} \mathrm{C}$. Perfusion with $\mathrm{Ca}^{2+}$-free Tyrode's solution for $5 \mathrm{~min}$ was followed first by $25 \pm 5 \mathrm{~min}$ perfusion with low $\mathrm{Ca}^{2+}(0.1 \mathrm{mmol} / \mathrm{L})$ Tyrode's solution containing $0.04-0.06 \mathrm{~g} / \mathrm{L}$ collagenase and $0.5-0.8 \mathrm{~g} / \mathrm{L} \mathrm{BSA}$ and then $5 \mathrm{~min}$ perfusion with collagenasefree Tyrode's solution containing $0.5-0.8 \mathrm{~g} / \mathrm{L}$ BSA. The heart was then minced and the cells were filtered through $200 \mu \mathrm{m}$ nylon mesh, resuspended in Kraft-Brühe (KB) solution, and stored at room temperature $\left(22-25^{\circ} \mathrm{C}\right)$ until use.

2.4. Cell Culture. The HEK293 cells that stably expressed the wild type HERG gene were kindly provided by Professor Xiaoyan Liu (Academy of Military Medical Sciences, Beijing, China). Dulbecco's Modified Eagle’s Medium 
(DMEM, Hyclone) supplemented with $10 \%(\mathrm{v} / \mathrm{v})$ fetal bovine serum (FBS, Gibco) and $1 \mathrm{mg} / \mathrm{mL}$ geneticin (G-418, Gibco), the cultures were passed every 3-5 days by use of a brief trypsin treatment. The cells were maintained at $37^{\circ} \mathrm{C}$ in $5 \%$ $\mathrm{CO}_{2}$ and plated on a glass culture dish 2-3 days before electrophysiological experiments.

2.5. Electrophysiological Recordings. All currents were recorded using the conventional whole-cell patch-clamp technique. Borosilicate glass electrodes had tip resistances of 1-3 $\mathrm{M} \Omega$ when filled with the pipette solution. All experiments were performed at room temperature $\left(22-23^{\circ} \mathrm{C}\right)$ using an Axopatch 200B amplifier (Axon Instrument, USA). Adequate series resistances (less than five times the pipette resistances) were usually attained within 10 min after the gigaohm seal was formed. Measurements were taken using an Axopatch 200B amplifier (Axon Instruments). The current signals were filtered via a $4 \mathrm{kHz}$, 4-pole low-pass filter and digitized with an AD-DA converter (Digidata 1440, Axon Instruments) for subsequent analysis using pCLAMP 10.0 software.

2.6. Statistical Analysis. The data were analyzed with the use of Data Processing System (Version 7.05). All data are expressed as means \pm SEM. Paired Student's $t$-tests were used for statistical comparisons when appropriate, and differences were considered significant at $P<0.05$.

\section{Results}

3.1. Effect of $G A$ on the $I_{K}$ of Guinea Pig Ventricular Myocytes. We first tested the effect of GA on $I_{\mathrm{K}}$ using guinea pig ventricular myocytes. $I_{\mathrm{K}}$ were recorded by applying voltage pulses ranging from -10 to $+80 \mathrm{mV}$ for $5 \mathrm{~s}$ from the holding potential of $-40 \mathrm{mV}$, and the repolarization potential was maintained at a constant $-30 \mathrm{mV}$ for the $I_{\mathrm{K} \text {,tail }}$ analysis. Figure 1(a) shows an example of a voltage-clamp recording from a single ventricular myocyte, with representative current traces given under control conditions and after exposure to $10 \mu \mathrm{M}$ GA. Under control conditions, the depolarizing steps activated time-dependent outward currents. The amplitude of the outward currents measured at the end of the pulse $\left(I_{\mathrm{K}}\right)$ increased with increasingly positive voltage steps. The current-voltage relationships for $I_{\mathrm{K} \text {,step }}$ and $I_{\mathrm{K} \text {,tail }}$ obtained at various concentrations of GA are shown in Figures 1(b) and 1(c). As the concentration of GA increased, the amplitude of $I_{\mathrm{K} \text {,step }}$ and $I_{\mathrm{K} \text {,tail }}$ decreased dose dependently (Figures $1(\mathrm{~d})$ and $1(\mathrm{e}))$. The $I_{\mathrm{K} \text {,step }}$ measured at $+80 \mathrm{mV}$ was $6.97 \pm 0.34 \mathrm{pA} / \mathrm{pF}$ under control conditions and decreased to $4.93 \pm 0.51 \mathrm{pA} / \mathrm{pF}$, $3.35 \pm 0.55 \mathrm{pA} / \mathrm{pF}$, and $2.12 \pm 0.29 \mathrm{pA} / \mathrm{pF}$ after application of 1 , 5 , and $10 \mu \mathrm{M} \mathrm{GA}$, respectively $(n=5, P<0.05)$. Meanwhile, the $I_{\mathrm{K} \text {,tail }}$ evoked after repolarization to $-30 \mathrm{mV}$ was $1.57 \pm 0.11$ $\mathrm{pA} / \mathrm{pF}$ under control conditions and decreased to $1.24 \pm 0.12$ $\mathrm{pA} / \mathrm{pF}, 0.67 \pm 0.15 \mathrm{pA} / \mathrm{pF}$ and $0.48 \pm 0.06 \mathrm{pA} / \mathrm{pF}$ in the presence of 1,5 and $10 \mu \mathrm{M} \mathrm{GA}$, respectively $(n=5, P<0.05)$. These results show that GA dose-dependently blocked $I_{\mathrm{K} \text {,step }}$ and $I_{\mathrm{K}, \text { tail }}$.
3.2. Effect of GA on $I_{K r}$ and $I_{K s}$ in Guinea Pig Ventricular Myocytes. To investigate the effects of GA on the rapid and slow components of the delayed rectifier currents in guineapig ventricular myocytes, we used a voltage clamp protocol designed to separate the currents electrophysiologically. The holding potential was maintained at $-40 \mathrm{mV}$. Our results revealed that depolarization to $+60 \mathrm{mV}$ activated both $I_{\mathrm{Kr}}$ and $I_{\mathrm{Ks}}$. Repolarization to $0 \mathrm{mV}$ revealed $I_{\mathrm{Ks}}$ as a deactivating $I_{\mathrm{Ks} \text {,tail }}$, and subsequent repolarization to $-40 \mathrm{mV}$ resulted in deactivation of $I_{\mathrm{Kr}}$. We confirmed that $2 \mu \mathrm{M}$ E-4031, a selective blocker of $I_{\mathrm{Kr}}$, blocked the rapid component of the delayed rectifier $\mathrm{K}^{+}$current but had no effect on $I_{\mathrm{Ks}}$ (Figure 2). As shown in Figures 2(b) and 2(c), 1, 5, and $10 \mu \mathrm{M}$ GA dose dependently inhibited $I_{\mathrm{Ks} \text {,tail }}$ and $I_{\mathrm{Kr} \text {,tail }}$. In the cells examined, $I_{\mathrm{Ks} \text {, tail }}$ measured at $0 \mathrm{mV}$ was $0.59 \pm 0.03 \mathrm{pA} / \mathrm{pF}$ under control conditions and decreased to $0.53 \pm 0.06 \mathrm{pA} / \mathrm{pF}$, $0.33 \pm 0.06 \mathrm{pA} / \mathrm{pF}$, and $0.16 \pm 0.03 \mathrm{pA} / \mathrm{pF}$ after application of 1,5 , and $10 \mu \mathrm{M} \mathrm{GA}$, respectively $(n=5, P<0.05)$. The $I_{\mathrm{Kr} \text {,tail }}$ evoked after repolarization to $-40 \mathrm{mV}$ was $1.57 \pm 0.11 \mathrm{pA} / \mathrm{pF}$ under control conditions and decreased to $0.57 \pm 0.06 \mathrm{pA} / \mathrm{pF}$, $0.29 \pm 0.02 \mathrm{pA} / \mathrm{pF}$ and $0.21 \pm 0.05 \mathrm{pA} / \mathrm{pF}$ in the presence of 1,5 and $10 \mu \mathrm{M}$ GA, respectively $(n=5, P<0.05)$. This result shows that GA blocks the rapid and slow components of delayed rectifier $\mathrm{K}^{+}$current.

\subsection{Inhibition of HERG $\mathrm{K}^{+}$Currents and Concentration-} Dependent Block by GA. The HERG current was elicited from the holding potential of $-80 \mathrm{mV}$ by test pulses ranging from -60 to $+30 \mathrm{mV}$ in $10 \mathrm{mV}$ steps. Each test pulse was followed by a repolarization step to $-50 \mathrm{mV}$, which evoked large, slowly decaying outward tail currents. Currents were recorded first under control conditions, and then GA $(5 \mu \mathrm{M})$ was washed into the bath for $10 \mathrm{~min}$, with the cell kept at the holding potential, before current recording commenced in the presence of the drug (Figure 3(a)). In the absence of drug, the $I-V$ relationship exhibited the characteristic bellshaped curve increasing from -40 to $0 \mathrm{mV}$, and owing to the fast C-type inactivation of HERG channels, it decreased with further depolarization. GA reduced both the HERG current $\left(I_{\text {step }}\right)$ during the test potentials and the tail current $\left(I_{\text {tail }}\right)$ after a test pulse to $0 \mathrm{mV}$ (Figures $3(\mathrm{c}$ ) and 3(d)). GA inhibited the tail current at all potentials, although voltage dependence was evident with a significantly weaker block at more negative potentials (Figure 3(d)).

GA blocked the HERG currents and the tail current in a concentration-dependent manner. The stimulus protocol used is illustrated in Figure 3(a). At GA concentrations of 1, 5 , and $10 \mu \mathrm{M}$, the HERG current amplitude at $0 \mathrm{mV}$ and the peak tail current amplitude were measured, normalized for each cell to the control value and then averaged $(n=5)$. The fractional block of $I_{\text {step }}$ was $20.46 \pm 2.7 \%$ in the $1 \mathrm{mM}$ group $(P<0.05), 29.93 \pm 3.1 \%$ in the $5 \mathrm{mM}$ group $(P<$ $0.05)$, and $56.38 \pm 4.2 \%$ in the $10 \mathrm{mM}$ group $(P<0.05)$; the corresponding fractional blocks of $I_{\text {tail }}$ were $19.26 \pm 2.5 \%$ $(P<0.05), 36.57 \pm 3.0 \%(P<0.05)$, and $55.29 \pm 3.6 \%$ $(P<0.05)$, respectively (Figure 4$)$. 


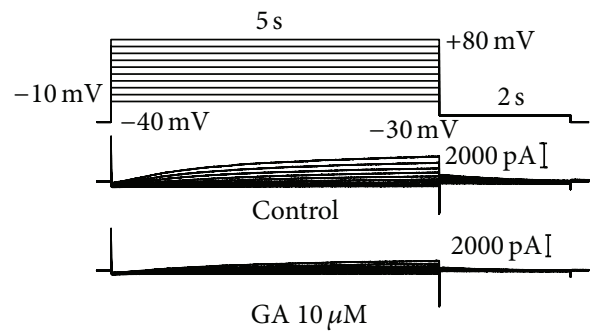

(a)

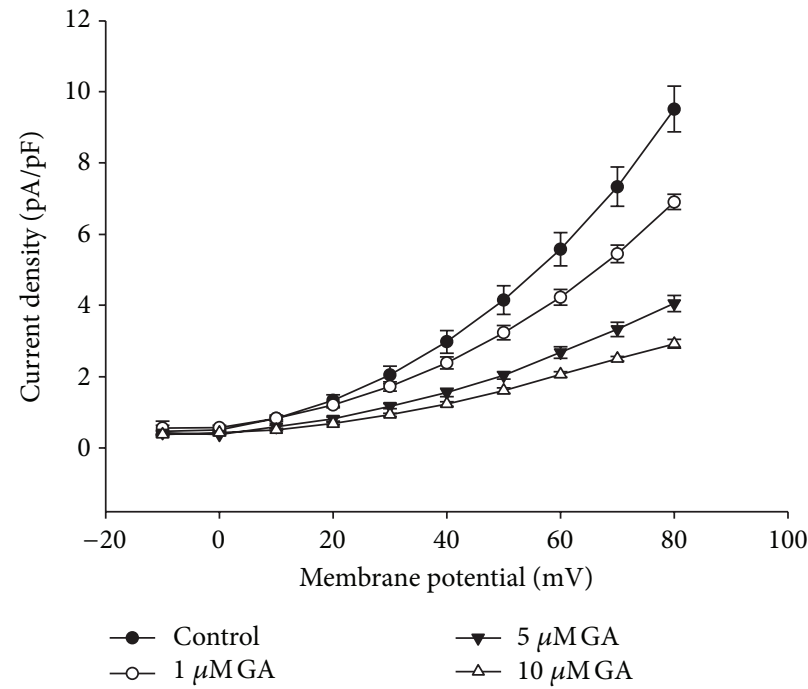

(b)

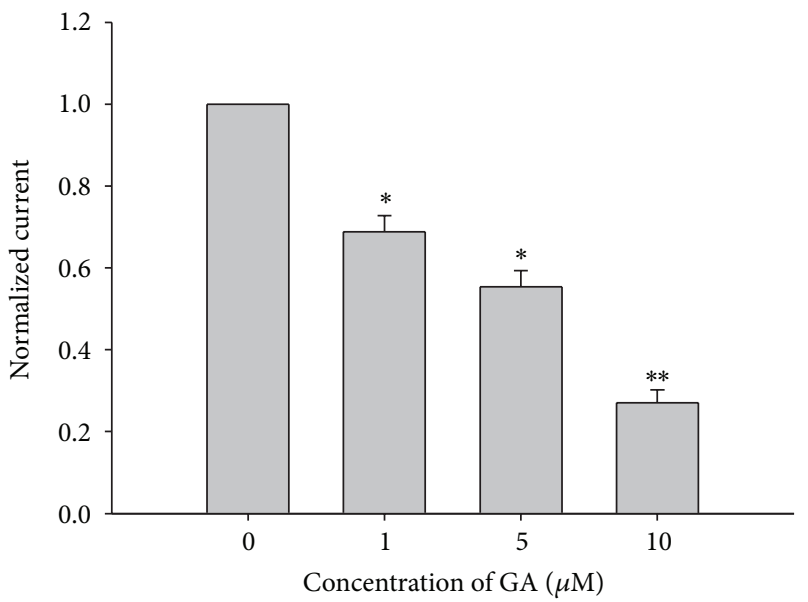

(d)

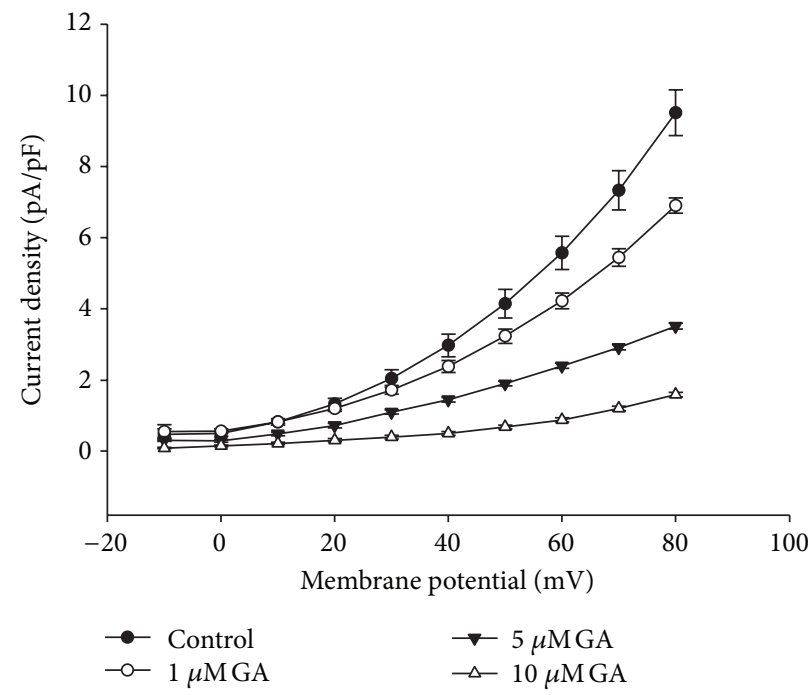

(c)

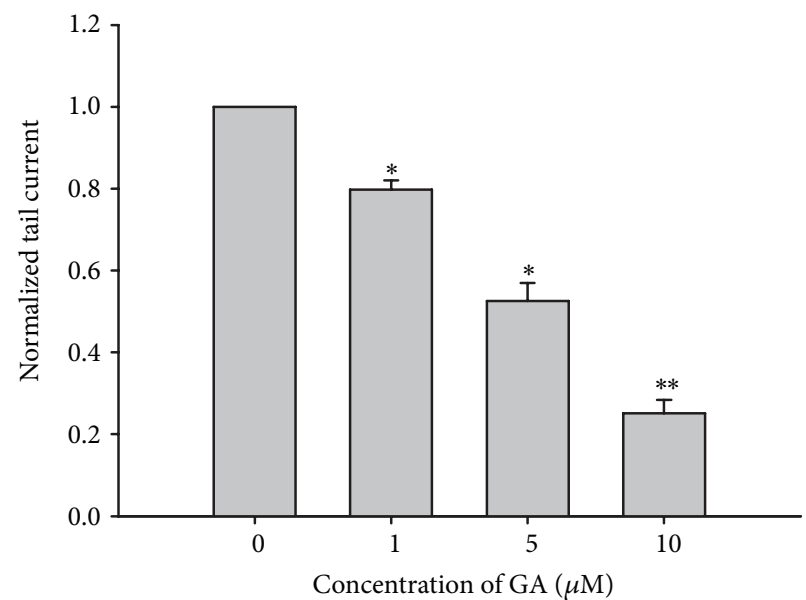

(e)

FIGURE 1: Effect of GA on the $I_{\mathrm{K}}$ of guinea pig ventricular myocytes. (a) Current traces elicited by $5 \mathrm{~s}$ test pulses from -10 to $+80 \mathrm{mV}$ with $10 \mathrm{mV}$ increments, and tail currents recorded at $-30 \mathrm{mV}$ for $2 \mathrm{~s}$. Representative traces of $I_{\mathrm{K}}$ recorded from the same cell under control condition and after applying GA. Current-voltage relationship of $I_{\mathrm{K}, \text { step }}(\mathrm{b})$ and $I_{\mathrm{K}, \text { tail }}(\mathrm{c})$ observed in five cells tested in the absence and presence of GA (1, 5 , and $10 \mu \mathrm{M})$. Summary of the effects of GA $(1,5$, and $10 \mu \mathrm{M})$ on $I_{\mathrm{K}, \text { step }}(\mathrm{d})$ and $I_{\mathrm{K}, \text { tail }}(\mathrm{e})$, normalized relative to the control current $(n=5$, $\left.{ }^{*} P<0.05,{ }^{* *} P<0.01\right)$.

3.4. Effects of GA on HERG Channel Kinetics. Drugs that block ion channels often alter the voltage dependence or kinetics of channel gating. Therefore, we examined the effects of GA on the voltage dependence of activation and rectification and on the kinetics of inactivation and deactivation. The activation curves were constructed by normalizing the tail currents recorded with the protocol used in Figure 3(a). The activation curve showed that the threshold voltage for HERG current activation was close to $-50 \mathrm{mV}$ and that it was fully activated with voltage steps to $-10 \mathrm{mV}$. The rate of activation 


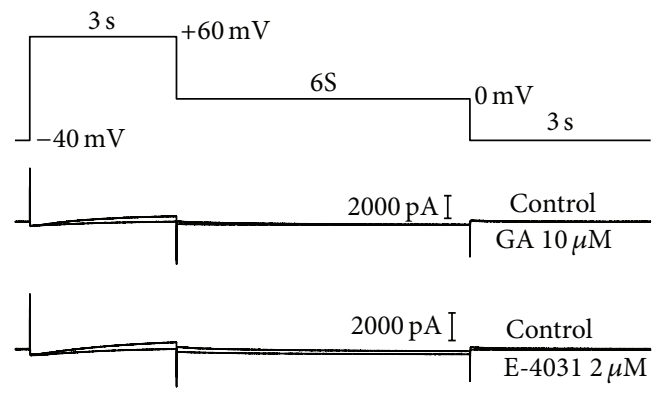

(a)

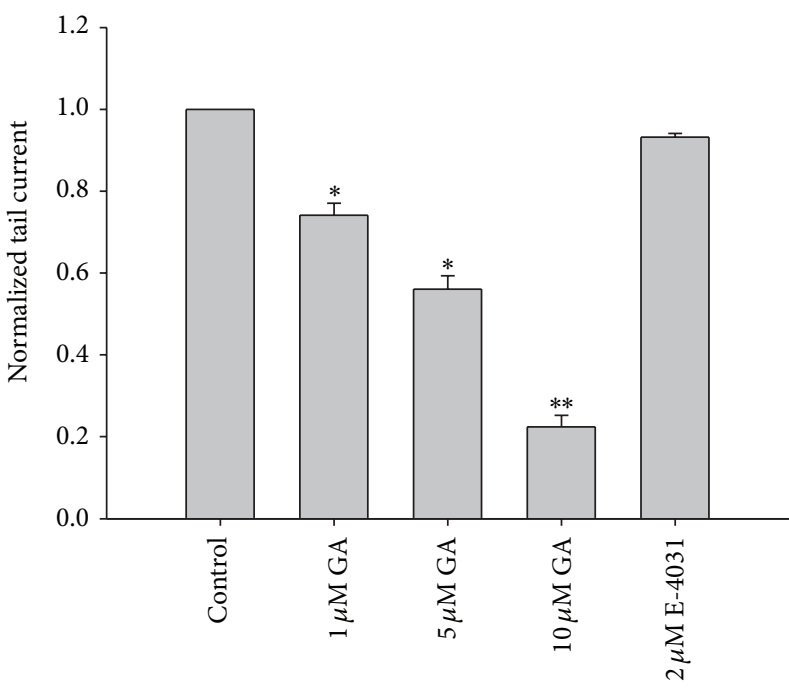

(b)

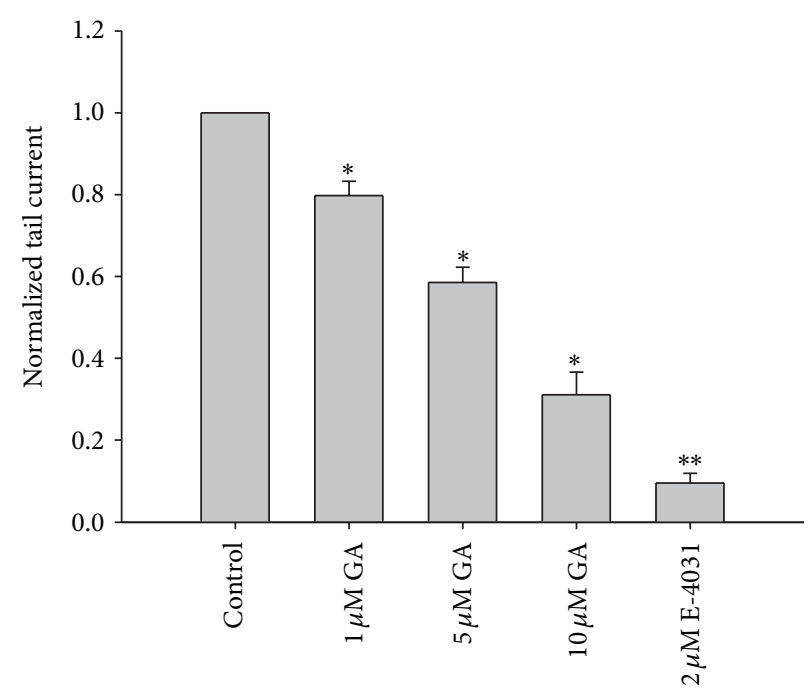

(c)

FIGURE 2: Effect of GA on the slow and rapid components of the delayed rectifier $\mathrm{K}^{+}$current in guinea pig ventricular myocytes. (a) Representative traces of the rapid $\left(I_{\mathrm{Kr}}\right)$ and slow $\left(I_{\mathrm{Ks}}\right)$ components of the delayed rectifier $\mathrm{K}^{+}$channel tail currents before and after treatment with $10 \mu \mathrm{M}$ GA and $2 \mu \mathrm{M} \mathrm{E}-4031$. The effects of 1,5 , and $10 \mu \mathrm{M} \mathrm{GA}$ and $2 \mu \mathrm{M} \mathrm{E}-4031$ on $I_{\mathrm{Ks} \text {,tail }}(\mathrm{b})$ and $I_{\mathrm{Kr} \text {,tail }}$ (c), normalized relative to the control current $(n=5, P<0.05)$. The tail current amplitudes were differences between peak outward current and the steady state current at the end of the repolarizing voltage pulses. $\left({ }^{*} P<0.05,{ }^{* *} P<0.01\right)$.

was similar before and after exposure to $5 \mu \mathrm{M}$ GA. $V_{1 / 2}$ values were $-19.83 \pm 2.36 \mathrm{mV}$ in the control and $-22.56 \pm 1.84 \mathrm{mV}$ in GA $(P>0.05, n=5)$. Thus, $5 \mu \mathrm{M}$ GA had little effect on the voltage dependence of activation (Figure $3(\mathrm{~b})$ ).

To measure inactivation, a special protocol was used that inactivated the channel at a holding potential of $40 \mathrm{mV}$, recovered the channel from inactivation at various potentials from -120 to $20 \mathrm{mV}$ in $10 \mathrm{mV}$ steps, and measured the resulting peak outward current at constant $20 \mathrm{mV}$ as a measure of steady-state inactivation (Figure 5(a)). Mean data from five cells were fitted to a Boltzmann function, yielding inactivation $V_{1 / 2}$ values of $-51.27 \pm 3.21 \mathrm{mV}$ in the control and $-62.68 \pm 2.85 \mathrm{mV}$ in $5 \mu \mathrm{M} \mathrm{GA}(P<0.05, n=5)$ (Figure $5(\mathrm{c}))$. The time course of the development of inactivation was also assessed. Monoexponential curve fitting of the inactivation time-course yielded time constant values (Figure $5(\mathrm{~b}) ; n=5$ ). From -120 to $-20 \mathrm{mV}$, the time constants of inactivation were significantly lower in the presence of $5 \mu \mathrm{M}$ GA $(P<0.05$, $n=5$ ) than in the absence of the drug.

The effect of GA on the onset of inactivation of the HERG current was investigated using a three-pulse protocol. The channels were first inactivated by clamping the membrane at $40 \mathrm{mV}$ followed by a prepulse to $-100 \mathrm{mV}$. This prepulse was sufficiently long to allow rapid recovery of channels from inactivation but short enough to prevent significant channel deactivation. Following recovery from the prepulse, a series of test pulses were delivered to potentials ranging from -120 to $20 \mathrm{mV}$, resulting in outward inactivating currents (Figure 6(a)). The time constants for the onset of inactivation were obtained by fitting exponential functions to the decaying current traces during the third pulse of the protocol and were significantly decreased following perfusion with $5 \mu \mathrm{M}$ GA $(P<0.05, n=5)$ (Figure 6(c)).

To determine recovery from inactivation, the fully activated $I-V$ protocol shown in Figure 6(b) was used: a depolarizing pulse to $40 \mathrm{mV}$ to inactivate the HERG channels, followed by different repolarizing pulses to test potentials between -120 and $20 \mathrm{mV}$ in $10 \mathrm{mV}$ steps. The prepulse potential at $40 \mathrm{mV}$ was positive enough to induce full conductance of the HERG channels but also inactivated many of the channels. The rate of recovery from inactivation was obtained by fitting a single exponential to the initial increase in tailcurrent amplitude, whereas the time constant of deactivation was ascertained by fitting a single exponential to the decay 

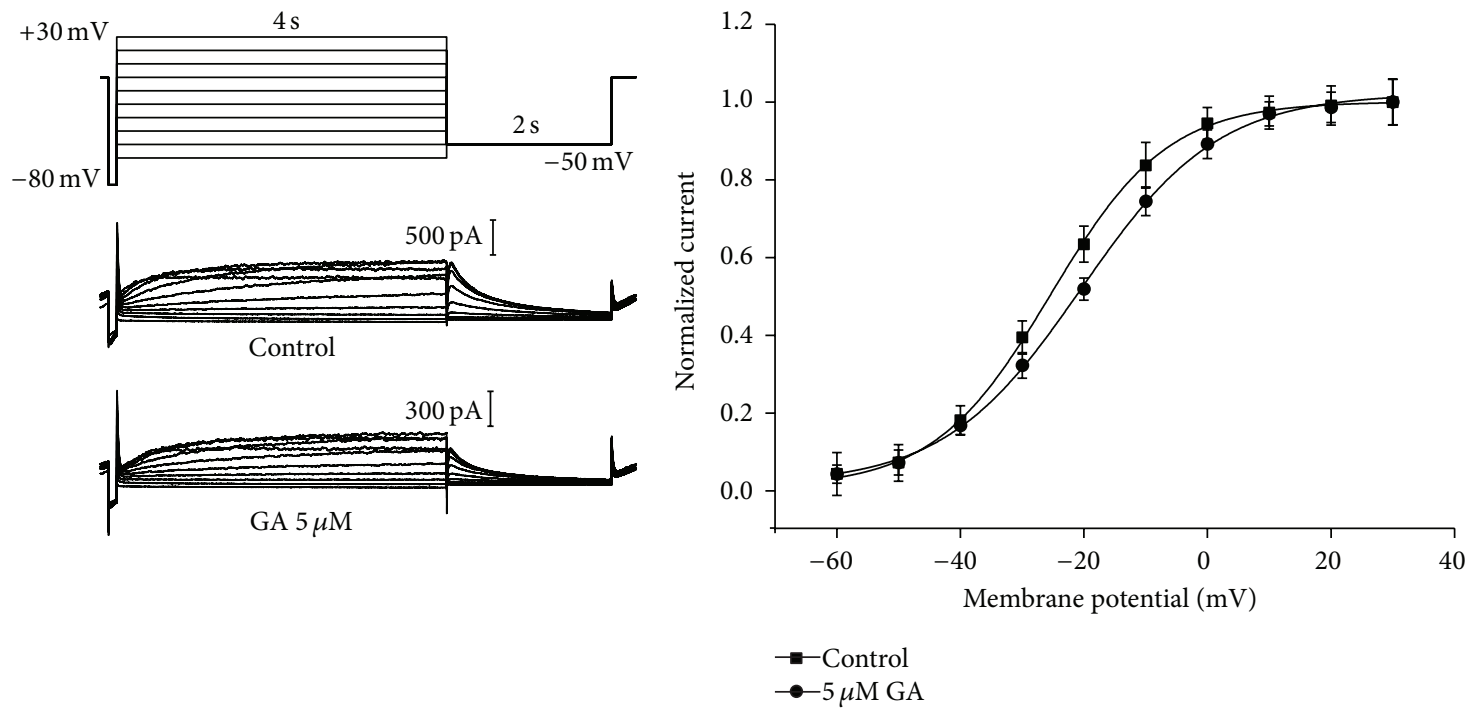

(a)

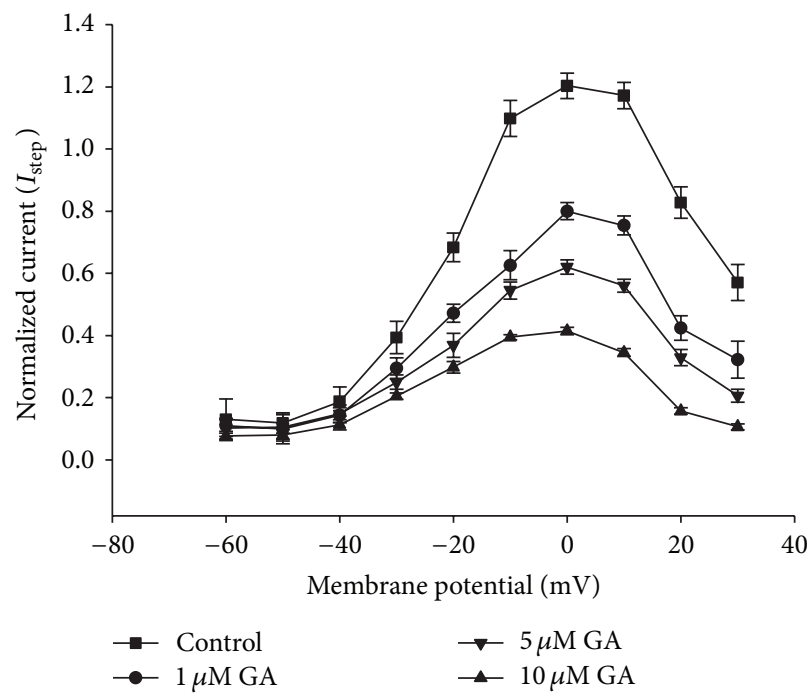

(c) (b)

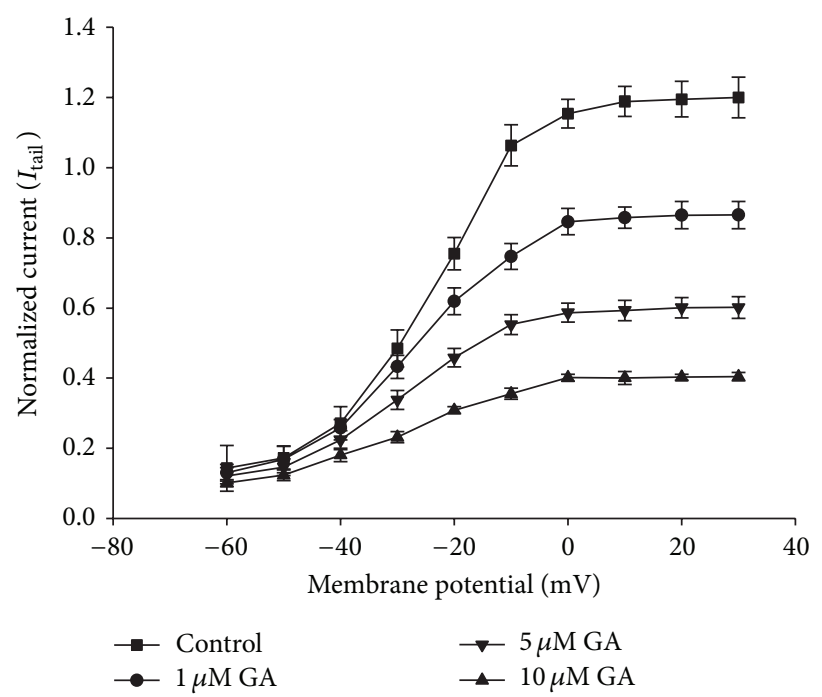

(d)

FIGURE 3: Current-voltage relationship for HERG channels and blockade by GA. (a) HERG currents are illustrated under control conditions and in the presence of $5 \mu \mathrm{M}$ GA recorded using the pulse protocol. (b) Voltage-dependent activation curves for the control and following GA exposure. Tail currents under control conditions and in the presence of $5 \mu \mathrm{M}$ GA were normalized and fitted to the Boltzmann sigmoidal function. There were no significant differences in half-activation voltage $\left(V_{1 / 2}\right)$ of $5 \mu \mathrm{M}$ compared with the control $(P>0.05, n=6)$. Data were expressed as mean \pm SEM. Statistical comparisons were made using a two-tailed Student's $t$-test. Normalized (to respective control values) $I-V$ relationships for current measured at the end of depolarizing steps (c) and tail currents (d) in the control and the presence of $1 \mu \mathrm{M}, 5 \mu \mathrm{M}$, and $10 \mu \mathrm{M}$ GA. Data are expressed as mean \pm SEM; $n=6$. Statistical comparisons were made using a two-tailed Student's $t$-test $(P<0.05$, $n=6)$.

of the tail current. However, $5 \mu \mathrm{M}$ GA did not change the deactivation rate significantly $(P>0.05, n=5)$ (Figure 6(d)).

\section{Discussion}

Cardiac $\mathrm{K}^{+}$channels play a pivotal role in maintaining normal cardiac electrical activity. They regulate the resting membrane potential and excitability, participate in repolarization, and determine the shape and duration of cardiac action potential. A malfunction of the $\mathrm{K}^{+}$channels due to either gene mutations or drug blockade alters not only cardiomyocyte excitability but also the electrical balance of depolarization and repolarization, which causes a long or short QT interval in the electrocardiogram (ECG) and underlies different types of cardiac arrhythmia [21,22]. Therefore, cardiac $\mathrm{K}^{+}$channels are important targets for antiarrhythmic drugs.

In the present study, we have firstly provided the evidence that the antiarrhythmic ionic mechanism of GA is related to the inhibition of potassium currents $\left(I_{\mathrm{Kr}}, I_{\mathrm{Ks}}\right)$ in guinea pig ventricular myocytes. The cardiac ion channel gene products 


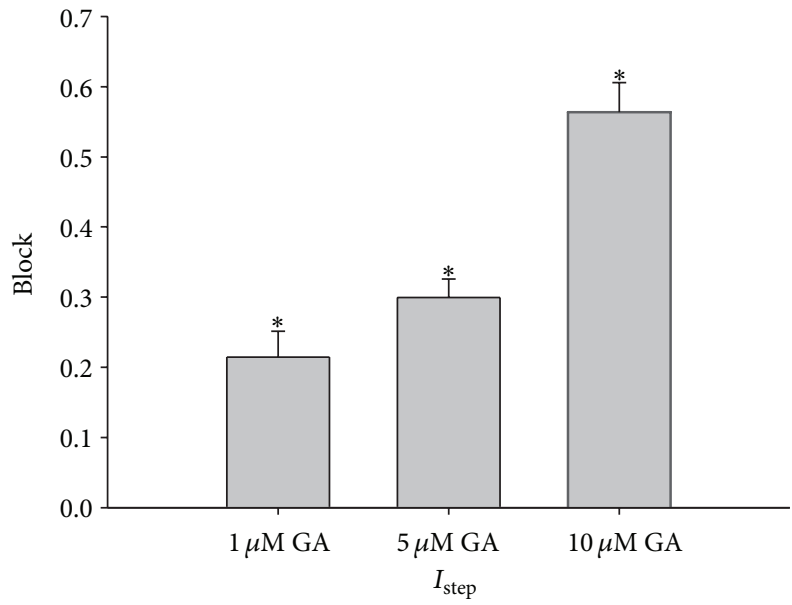

(a)

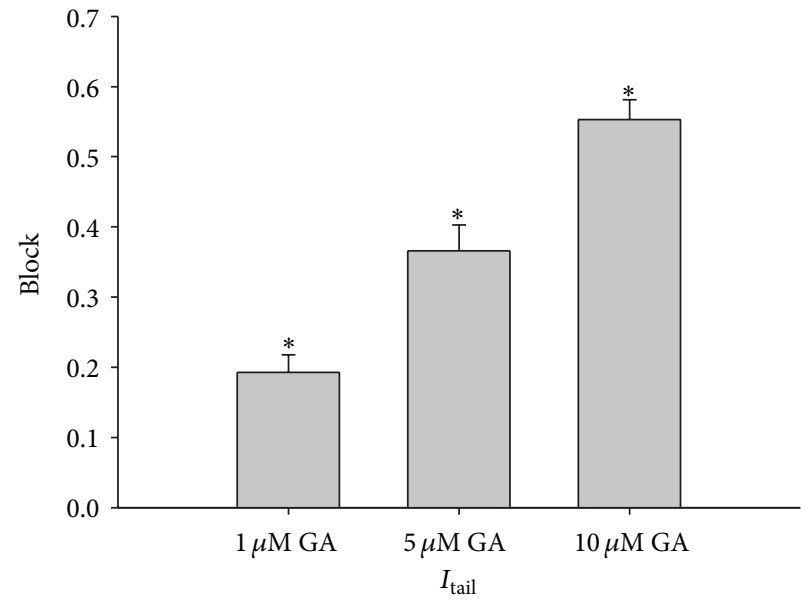

(b)

FIGURE 4: Inhibitory effect of GA on HERG current. Mean fractional block of HERG at a test potential of $0 \mathrm{mV}$ at GA concentrations of 1, 5 , and $10 \mu \mathrm{M}$ was determined in HEK293 cells that stably expressed HERG channels.

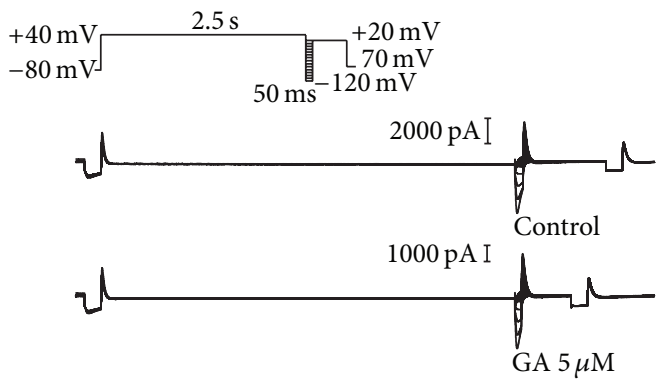

(a)

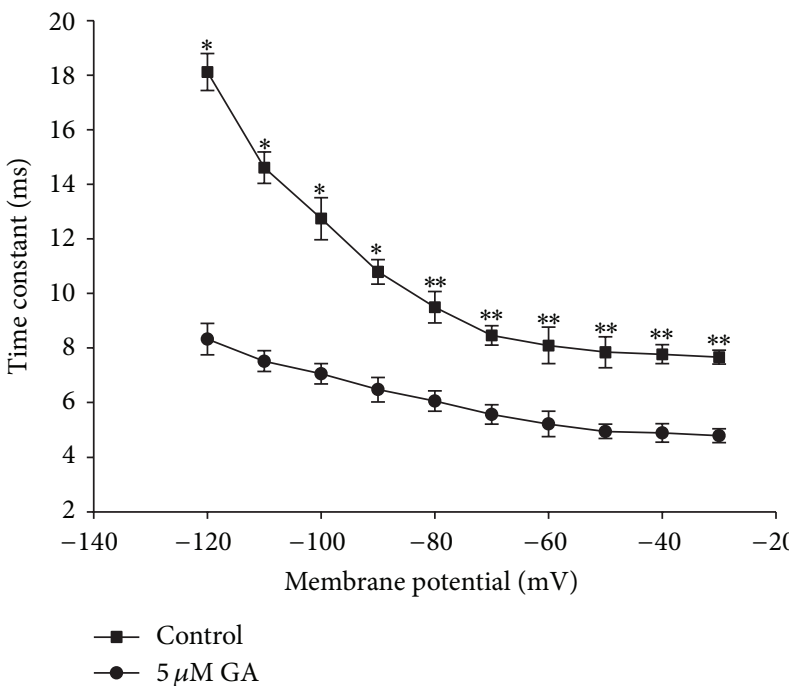

(b)

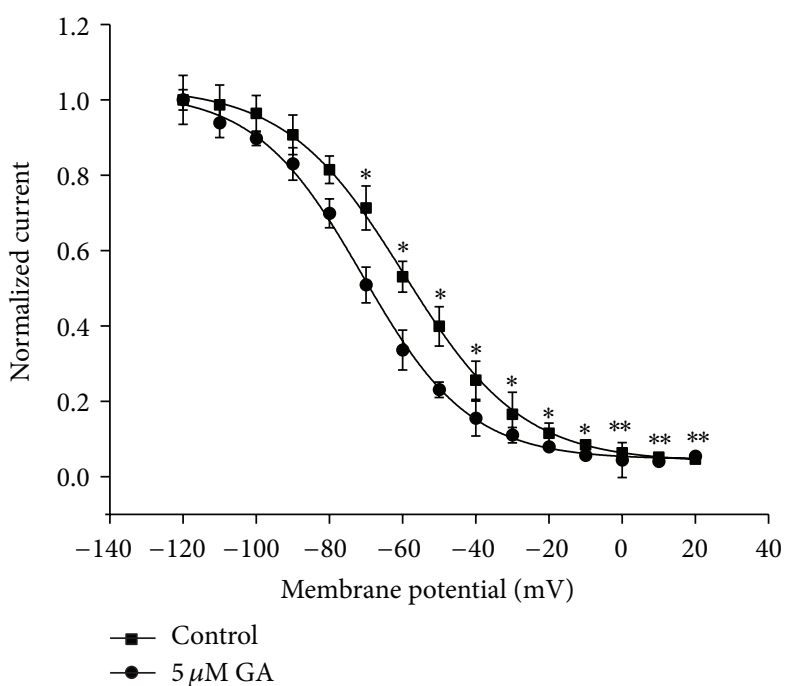

(c)

FIGURE 5: Effect of GA on normalized steady-state inactivation curves. (a) Representative active current traces for steady-state inactivation using a three-pulse protocol with various interpulse repolarization levels (from -120 mV to $20 \mathrm{mV}$ ). (b) The time constant of inactivation was significantly reduced at all membrane potential values $(P<0.05, n=5)$. (c) Normalized steady-state inactivation curves before and after $5 \mu \mathrm{M}$ GA application $(P<0.05, n=5)$. Data were expressed as mean \pm SEM. Solid lines represent fits to the Boltzmann sigmoidal function. Statistical comparisons were made using a two-tailed Student's $t$-test. $\left({ }^{*} P<0.05,{ }^{* *} P<0.01\right)$. 


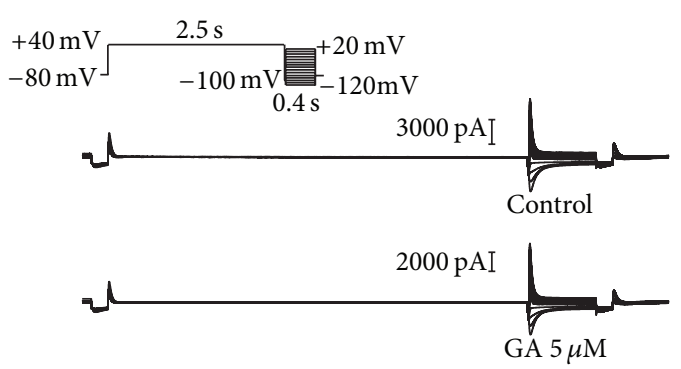

(a)

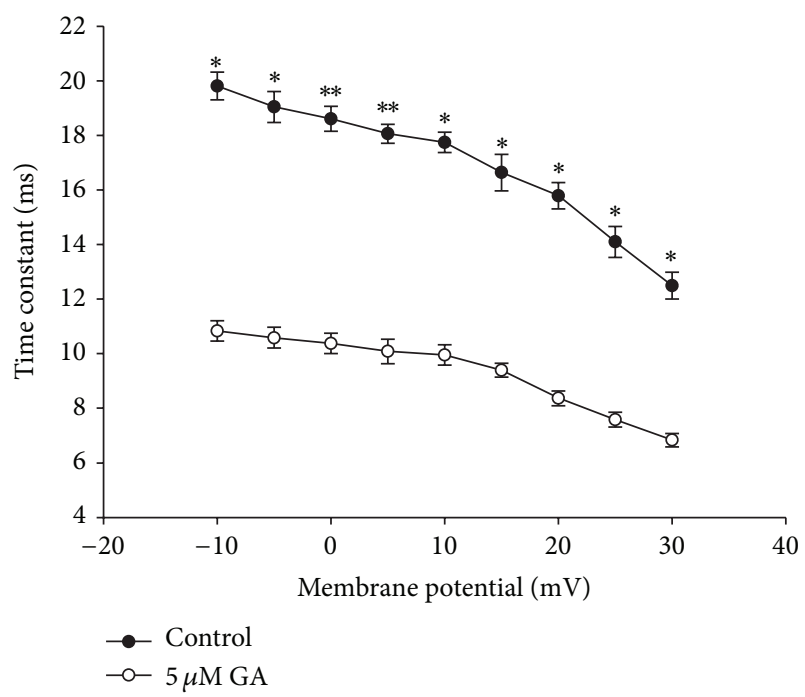

(c)
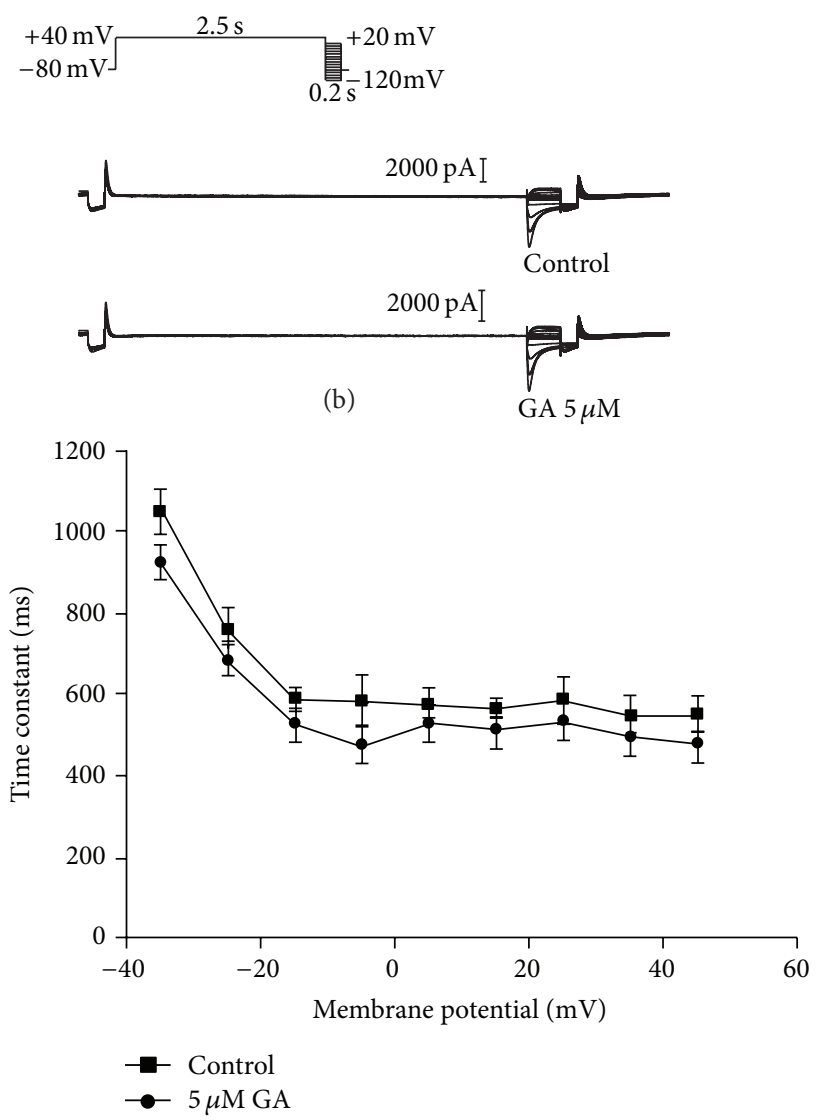

(d)

FIGURE 6: Effect of GA on kinetic time constants. (a) Representative current traces for the onset of inactivation of the HERG current using the protocol are shown on the figure. The time constants for the onset of inactivation were obtained by fitting the exponential function to the decaying current traces during the third pulse of the protocol. (b) Representative current traces for HERG current recovery from inactivation elicited by the protocol are shown on the figure. (c) Time constants for onset of inactivation were plotted against membrane potential. Data were expressed as mean $\pm \operatorname{SEM}(P<0.05, n=5)$. (d) Time constants for deactivation in the absence or presence of $5 \mu \mathrm{M}$ GA $(P>0.05$, $n=5$ ). Solid lines represent fits of a single exponential function to the descending phase of the tail current. Data were expressed as mean \pm SEM, and statistical comparisons were made using a two-tailed Student's $t$-test. $\left({ }^{*} P<0.05,{ }^{* *} P<0.01\right)$.

that are targets for GA are unknown. However, previous studies have demonstrated that the peak and late $I_{\mathrm{Na}}$, studied in the Xenopus oocytes expressing either human $\mathrm{Na}_{\mathrm{V}} 1.5$ or mutant $\mathrm{Na}_{\mathrm{V}} 1.5-\Delta \mathrm{KPQ}$ of the $\alpha$-subunit channel, were strongly reduced by GA [19], resulting in a prolongation of the action potential. We therefore tested GA for a possible block of HERG expressed in HEK293 cells. The results confirmed that GA blocks HERG.

One of the main objectives of studying ionic channels is to provide a theoretical basis for the clinical treatment of tachyarrhythmia. Many active ingredients of Chinese medicine could block the HERG channel, decrease $I_{\mathrm{K}}$, and lead to the acquired long QT syndrome, which makes the channel the therapeutic target for anti-arrhythmia [23]. It is thought that HERG channel inactivation is important in channel blocking by some (but not all) drugs, either by increasing drugbinding affinity or by facilitating the optimal orientation of the S6 aromatic residues to which drugs bind. In this study, the extent of channel inactivation was significantly altered (Figure 5(c)), and the time course of inactivation seemed to be accelerated (Figure 5(b)). Furthermore, the time constants for the onset of inactivation were significantly smaller following perfusion with GA (Figure 6(c)). These effects of GA on channel kinetics were consistent with affinity for the inactivated state, suggesting that GA blocks the HERG channel by affecting its inactivation but not its activation. Our results demonstrated that GA has inhibitory effects on $I_{\mathrm{Kr}}, I_{\mathrm{Ks}}$ in guinea pig ventricular myocytes, and the HERG potassium channel, and the inhibition was in a concentration-dependent manner. The increase in action potential duration induced by GA is mainly due to its blocking effects on $I_{\mathrm{Kr}}, I_{\mathrm{Ks}}$, and HERG and are its major mechanisms of antiarrhythmic action.

$I_{\mathrm{Kr}}$ and $I_{\mathrm{Ks}}$ are important in cardiac repolarization [24]. $I_{\mathrm{Kr}}$ channels open rapidly upon depolarization of the action potential but are quickly inactivate. The channel inactivation is released following repolarization with a slow deactivation [25]. Owing to this inward rectification property, $I_{\mathrm{Kr}}$ contributes a little during the plateau of the cardiac action 
potential and progressively increases at phase 3 repolarization of the action potential [26]. Therefore, $I_{\mathrm{Kr}}$ is pivotal in cardiac repolarization, especially in the later phases of the action potential, due to its unique kinetics. $I_{\mathrm{Ks}}$ activates slowly with almost no inactivation after activation [25, 27] and contributes to the phase 2 slow repolarization of cardiac action potential. $I_{\mathrm{Ks}}$ has been demonstrated in cardiac tissues/myocytes from various species including human [24, $26,27]$. The physiological contribution of $I_{\mathrm{Ks}}$ to the human ventricular action potential is limited; however, during tonic sympathetic stimulation or when the cardiac repolarization reserve is attenuated, $I_{\mathrm{Ks}}$ becomes important in limiting APD prolongation owing to its slow deactivation [26]. $I_{\mathrm{Ks}}$ is expressed heterogeneously in different regions of the heart. In the canine ventricle, $I_{\mathrm{Ks}}$ density is greater in epicardial and endocardial cells than in the M cells $[28,29]$. This lower $I_{\mathrm{Ks}}$ density in the $\mathrm{M}$ cells is considered to be related to the steeper $A P D$ rate relationship and their greater tendency to display longer APD and to develop EADs at slow heart rates or in response to QT-prolonging drugs [29].

Any abnormality in channel density or function (upor downregulation) may result in changes of currents and APD, even inducing arrhythmias. The inhibition of $I_{\mathrm{Kr}}$, $I_{\mathrm{Ks}}$, and HERG by GA would induce a prolongation of APD, which could contribute to its antiarrhythmic actions because prolongation of APD could prevent or terminate the reentrant excitation and prolong the refractory period. Class III antiarrhythmic agents, blockers of $I_{\mathrm{Kr}}$ such as dsotalol, exert a proarrhythmic effect with reverse frequencydependent manner, which is largely attenuated at fast rates and enhanced at lower stimulation frequencies. This reverse frequency-dependent effect [30] could lead to an increase in the dispersion of repolarization and favor the occurrence of cardiac arrhythmias. Jurkiewicz and Sanguinetti [31] proposed that the reverse frequency-dependent effect on APD of typical class III agents is a consequence of selective blockade of $I_{\mathrm{Kr}} . I_{\mathrm{Kr}}$ blockers prolong atrial and ventricular APD and the QT interval and can cause TdP, which can degenerate into ventricular fibrillation and sudden cardiac death [2]. Proarrhythmia induced by $I_{\mathrm{Kr}}$ blockers is related to [3235] (a) excessive prolongation of APD near plateau voltages, which favor the development of early after-depolarizations; (b) a more marked prolongation of the APD in $M$ cells than in subepicardial or subendocardial ventricular muscle, possibly because of the relative scarcity of $I_{\mathrm{Ks}}$ in $\mathrm{M}$ cells [29]. Thus, triggered focal activity and ventricular reentry associated with increased inhomogeneity of repolarization across the ventricular wall would lead to the development of TdP $[3,4]$. It has been suggested that $I_{\mathrm{Ks}}$ accumulation at increased frequencies decreases the relative importance of $I_{\mathrm{Kr}}$, reducing the impact of $I_{\mathrm{Kr}}$ blockade on APD prolongation. The authors suggested that the compounds which inhibit $I_{\mathrm{Ks}}$ might be devoid of reverse use-dependence. Actually, the agent that blocks both components of $I_{\mathrm{K}}$ might have a more consistent effect on action potentials at different frequencies and a better safety profile than a specific $I_{\mathrm{Kr}}$ blocker [36].
Control of cardiac electrical activity is well organized by an array of ion channels activated with a delicate balance between inward and outward ion currents [37]. Upon receiving an incoming impulse, cardiac cells are excited with rapid membrane depolarization followed by a relatively slow repolarization. Repolarization disorders, either excessive slowing or acceleration of the rate, can cause electrical perturbations resulting in cardiac arrhythmias, while excessive blockade of the HERG channel might increase the risk of arrhythmogenic activities. A good antiarrhythmic drug should affect multiple channels and keep invalids free from further episodes of arrhythmia [23]. Taking this into consideration, the drugs currently available in clinics are not satisfactory. Previous studies have revealed that GA can block peak and late $I_{\mathrm{Na}}[19,20]$. In our task group, the results suggested that GA not only blocks $I_{\mathrm{Kr}}$ (HERG) and $I_{\mathrm{Ks}}$ but also inhibits $I_{\mathrm{Ca}-\mathrm{L}}$. The effect of GA on multiple channels might make it a promising antiarrhythmic that can lead the cardiac cell to restore normal sinus rhythm and prevent further arrhythmia. Further basic and clinical studies will be needed to explore whether GA has proarrhythmic actions.

\section{Conclusion}

In conclusion, our study demonstrated that GA has an inhibitory effect on $I_{\mathrm{K}}\left(I_{\mathrm{Kr}}, I_{\mathrm{Ks}}\right)$ and the HERG potassium channel expressed in HEK293 cells. The results indicate that the antiarrhythmic activity and prolonged action potential of GA could be due to the blocking of $I_{\mathrm{K}}\left(I_{\mathrm{Kr}}\right.$, $I_{\mathrm{Ks}}$ ) and the HERG channel. It is thought that a good antiarrhythmic drug should affect multiple channels and be able to restore normal sinus rhythm and keep patients free from further episodes of arrhythmia. GA not only blocks the HERG channel, $I_{\mathrm{K}}\left(I_{\mathrm{Kr}}, I_{\mathrm{Ks}}\right)$, but also inhibits $I_{\mathrm{Na}}$, so the results reveal that it has significant potential for development as a novel antiarrhythmic agent, particularly targeting the genesis of arrhythmias. Therefore, our findings might help to elucidate the traditional use of licorice in the treatment of cardiovascular disorders. Nonetheless, further evaluation of the therapeutic potential of GA is warranted.

\section{Authors' Contribution}

Delin Wu and Linqing Jiang contributed equally to the paper.

\section{Acknowledgments}

This work was supported by a Grant from the Beijing Key Disciplines Project of Traditional Chinese Medicine (no. JZZ-312) and National Natural Science Foundation of China (no. 81273890) to Dr Hongjin Wu. The authors thank Drs. Jianquan Zheng and Xiaoyan Liu (Beijing Institute of Pharmacology and Toxicology, Beijing, China) for generously providing the HEK293 cells that stably expressed the wild type HERG gene. 


\section{References}

[1] D. Darbar and D. M. Roden, "Future of antiarrhythmic drugs," Current Opinion in Cardiology, vol. 21, no. 4, pp. 361-367, 2006.

[2] C. E. Hill, H. Hickey, and S. L. Sandow, "Role of gap junctions in acetylcholine-induced vasodilation of proximal and distal arteries of the rat mesentery," Journal of the Autonomic Nervous System, vol. 81, no. 1-3, pp. 122-127, 2000.

[3] T. Murai, K. Muraki, Y. Imaizumi, and M. Watanabe, "Levcromakalim causes indirect endothelial hyperpolarization via a myo-endothelial pathway," The British Journal of Pharmacology, vol. 128, no. 7, pp. 1491-1496, 1999.

[4] H. Fukuta, M. Koshita, Y. Yamamoto, and H. Suzuki, "Inhibition of the endothelium-dependent relaxation by $18 \beta$-glycyrrhetinic acid in the guinea-pig aorta," Japanese Journal of Physiology, vol. 49, no. 3, pp. 267-274, 1999.

[5] H. J. Taylor, A. T. Chaytor, W. H. Evans, and T. M. Griffith, "Inhibition of the gap junctional component of endotheliumdependent relaxations in rabbit iliac artery by $18-\alpha$ glycyrrhetinic acid," The British Journal of Pharmacology, vol. 125, no. 1, pp. 1-3, 1998.

[6] S. C. Kwon, W. B. Pyun, G. Y. Park, H. Choi, K. Paik, and B. Kang, "The involvement of $\mathrm{K}^{+}$channels and the possible pathway of EDHF in the rabbit femoral artery," Yonsei Medical Journal, vol. 40, no. 4, pp. 331-338, 1999.

[7] C. Fiore, M. Eisenhut, R. Krausse et al., "Antiviral effects of Glycyrrhiza species," Phytotherapy Research, vol. 22, no. 2, pp. 141-148, 2008.

[8] B. Ploeger, T. Mensinga, A. Sips, W. Seinen, J. Meulenbelt, and J. DeJongh, "The pharmacokinetics of glycyrrhizic acid evaluated by physiologically based pharmacokinetic modeling," Drug Metabolism Reviews, vol. 33, no. 2, pp. 125-147, 2001.

[9] M. L. Parisella, T. Angelone, A. Gattuso, M. C. Cerra, and D. Pellegrino, "Glycyrrhizin and glycyrrhetinic acid directly modulate rat cardiac performance," Journal of Nutritional Biochemistry, vol. 23, no. 1, pp. 69-75, 2012.

[10] D. Armanini, C. Fiore, M. J. Mattarello, J. Bielenberg, and M. Palermo, "History of the endocrine effects of licorice," Experimental and Clinical Endocrinology and Diabetes, vol. 110, no. 6, pp. 257-261, 2002.

[11] V. Battaglia, A. M. Brunati, C. Fiore et al., "Glycyrrhetinic acid as inhibitor or amplifier of permeability transition in rat heart mitochondria," Biochimica et Biophysica Acta, vol. 1778, no. 1, pp. 313-323, 2008.

[12] K. S. Kilgore, E. J. Tanhehco, J. L. Park, K. B. Naylor, M. B. Anderson, and B. R. Lucchesi, "Reduction of myocardial infarct size in vivo by carbohydrate-based glycomimetics," Journal of Pharmacology and Experimental Therapeutics, vol. 284, no. 1, pp. 427-435, 1998.

[13] A. M. Aly, L. Al-Alousi, and H. A. Salem, "Licorice: a possible anti-inflammatory and anti-ulcer drug," AAPS PharmSciTech, vol. 6, no. 1, pp. E74-E82, 2005.

[14] J. R. Lee, S. J. Park, H. S. Lee et al., "Hepatoprotective activity of licorice water extract against Cadmium-induced toxicity in rats," Evidence-Based Complementary and Alternative Medicine, vol. 6, no. 2, pp. 195-201, 2009.

[15] H. Hibasami, H. Iwase, K. Yoshioka, and H. Takahashi, "Glycyrrhizin induces apoptosis in human stomach cancer KATO III and human promyelotic leukemia HL-60 cells," International Journal of Molecular Medicine, vol. 16, no. 2, pp. 233-236, 2005.

[16] A. Rodríguez-Sinovas, D. García-Dorado, M. Ruiz-Meana, and J. Soler-Soler, "Protective effect of gap junction uncouplers given during hypoxia against reoxygenation injury in isolated rat hearts," The American Journal of Physiology-Heart and Circulatory Physiology, vol. 290, no. 2, pp. H648-H656, 2006.

[17] F. Goubaeva, M. Mikami, S. Giardina, B. Ding, J. Abe, and J. Yang, "Cardiac mitochondrial connexin 43 regulates apoptosis," Biochemical and Biophysical Research Communications, vol. 352, no. 1, pp. 97-103, 2007.

[18] J. Y. Yang, H. J. Wu, and D. L. Wu, "Effects of glycyrretinic acid on sodium ion channel currents of rats' ventricular myocardial cells," Zhongguo Zhong Xi Yi Jie He Za Zhi, vol. 32, no. 7, pp. 944-947, 2012.

[19] Y. Du, S. Zhang, H. Wu et al., "Glycyrretinic acid blocks cardiac sodium channels expressed in Xenopus oocytes," Journal of Ethnopharmacology, vol. 125, no. 2, pp. 318-323, 2009.

[20] Y. M. Du, C. K. Xia, N. Zhao, Q. Dong, M. Lei, and J. H. Xia, "18 $\beta$-glycyrrhetinic acid preferentially blocks late Na current generated by $\delta$ KPQ Nav1.5 channels," Acta Pharmacologica Sinica, vol. 33, no. 6, pp. 752-760, 2012.

[21] P. J. Kannankeril and D. M. Roden, "Drug-induced long QT and torsade de pointes: recent advances," Current Opinion in Cardiology, vol. 22, no. 1, pp. 39-43, 2007.

[22] W. Zareba and I. Cygankiewicz, "Long QT syndrome and short QT syndrome," Progress in Cardiovascular Diseases, vol. 51, no. 3, pp. 264-278, 2008.

[23] H. J. Wu, A. R. Zou, F. Xie et al., "Effect of matrine on human ether a go-go related gene (HERG) channels expressed in Chinese hamster ovary cells," Chinese Journal of Integrative Medicine, vol. 16, no. 5, pp. 430-434, 2010.

[24] G. R. Li, J. Feng, L. Yue, M. Carrier, and S. Nattel, "Evidence for two components of delayed rectifier $\mathrm{K}^{+}$current in human ventricular myocytes," Circulation Research, vol. 78, no. 4, pp. 689-696, 1996.

[25] M. C. Sanguinetti and N. K. Jurkiewicz, "Two components of cardiac delayed rectifier $\mathrm{K}^{+}$current. Differential sensitivity to block by class III antiarrhythmic agent," Journal of General Physiology, vol. 96, no. 1, pp. 195-215, 1990.

[26] N. Jost, L. Virág, M. Bitay et al., "Restricting excessive cardiac action potential and QT prolongation: a vital role for IKs in human ventricular muscle," Circulation, vol. 112, no. 10, pp. 1392-1399, 2005.

[27] F. Charpentier, J. Mérot, G. Loussouarn, and I. Baró, "Delayed rectifier $\mathrm{K}^{+}$currents and cardiac repolarization," Journal of Molecular and Cellular Cardiology, vol. 48, no. 1, pp. 37-44, 2010.

[28] G. R. Li, C. P. Lau, A. Ducharme, J. C. Tardif, and S. Nattel, "Transmural action potential and ionic current remodeling in ventricles of failing canine hearts," The American Journal of Physiology-Heart and Circulatory Physiology, vol. 283, no. 3, pp. H1031-H1041, 2002.

[29] D. W. Liu and C. Antzelevitch, "Characteristics of the delayed rectifier current $(\mathrm{I}(\mathrm{Kr})$ and $\mathrm{I}(\mathrm{Ks}))$ in canine ventricular epicardial, midmyocardial, and endocardial myocytes: a weaker $\mathrm{I}(\mathrm{Ks})$ contributes to the longer action potential of the M cell," Circulation Research, vol. 76, no. 3, pp. 351-365, 1995.

[30] L. M. Hondeghem and D. J. Snyders, "Class III antiarrhythmic agents have a lot of potential but a long way to go. Reduced effectiveness and dangers of reverse use dependence," Circulation, vol. 81, no. 2, pp. 686-690, 1990.

[31] N. K. Jurkiewicz and M. C. Sanguinetti, "Rate-dependent prolongation of cardiac action potentials by a methanesulfonanilide class III antiarrhythmic agent: specific block of rapidly activating delayed rectifier $\mathrm{K}^{+}$current by dofetilide," Circulation Research, vol. 72, no. 1, pp. 75-83, 1993. 
[32] D. M. Roden, J. R. Balser, A. L. George Jr., and M. E. Anderson, "Cardiac ion channels," Annual Review of Physiology, vol. 64, pp. 431-475, 2002.

[33] J. Tamargo, "Drug-induced torsade de pointes: from molecular biology to bedside," Japanese Journal of Pharmacology, vol. 83, no. 1, pp. 1-19, 2000.

[34] W. Haverkamp, G. Breithardt, A. J. Camm et al., "The potential for QT prolongation and pro-arrhythmia by non-antiarrhythmic drugs: clinical and regulatory implications: report on a policy conference of the european society of cardiology," Cardiovascular Research, vol. 47, no. 2, pp. 219-233, 2000.

[35] W. S. Redfern, L. Carlsson, A. S. Davis et al., "Relationships between preclinical cardiac electrophysiology, clinical QT interval prolongation and torsade de pointes for a broad range of drugs: evidence for a provisional safety margin in drug development," Cardiovascular Research, vol. 58, no. 1, pp. 32-45, 2003.

[36] P. T. Sager, P. Uppal, C. Follmer, M. Antimisiaris, C. Pruitt, and B. N. Singh, "Frequency-dependent electrophysiologic effects of amiodarone in humans," Circulation, vol. 88, no. 3, pp. 10631071, 1993.

[37] J. M. Nerbonne and R. S. Kass, "Molecular physiology of cardiac repolarization," Physiological Reviews, vol. 85, no. 4, pp. 12051253, 2005. 


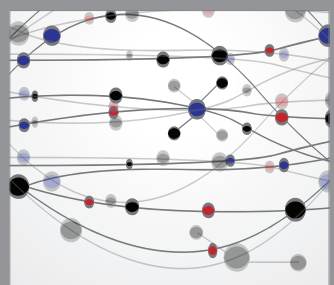

The Scientific World Journal
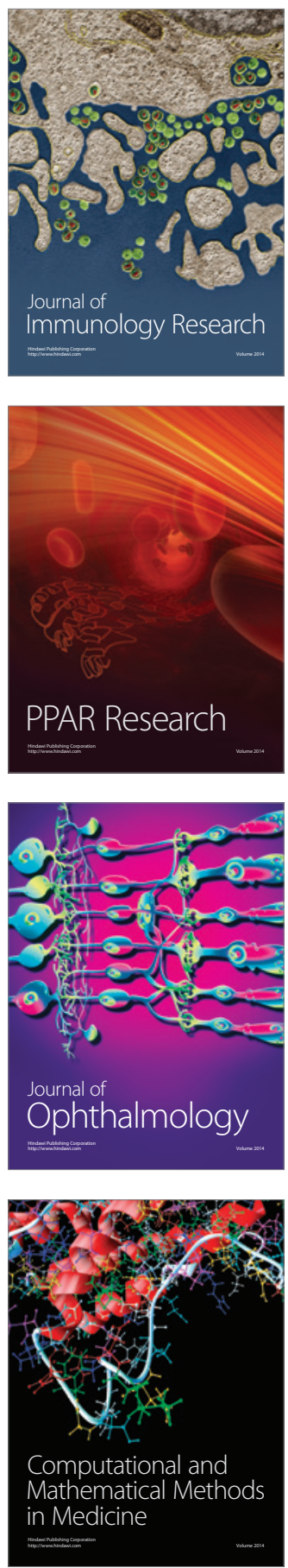

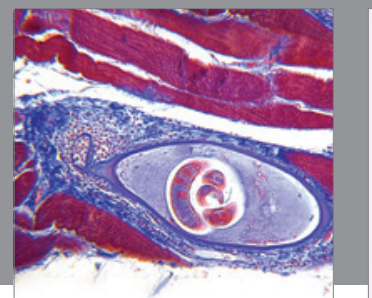

Gastroenterology

Research and Practice
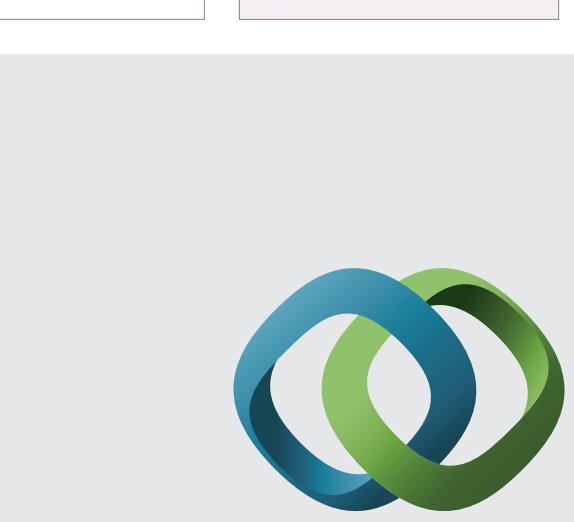

\section{Hindawi}

Submit your manuscripts at

http://www.hindawi.com
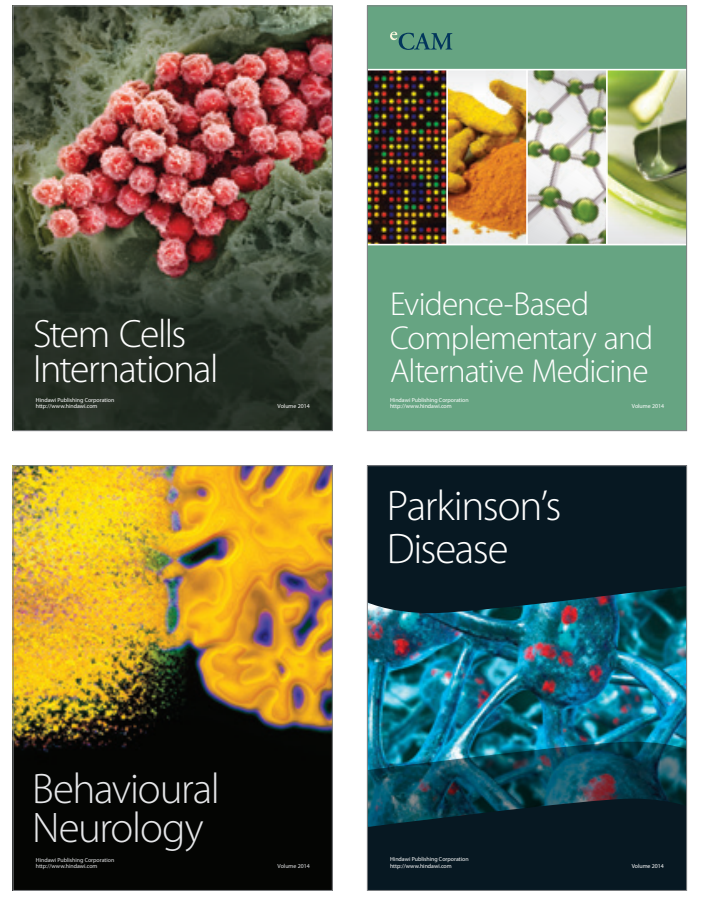
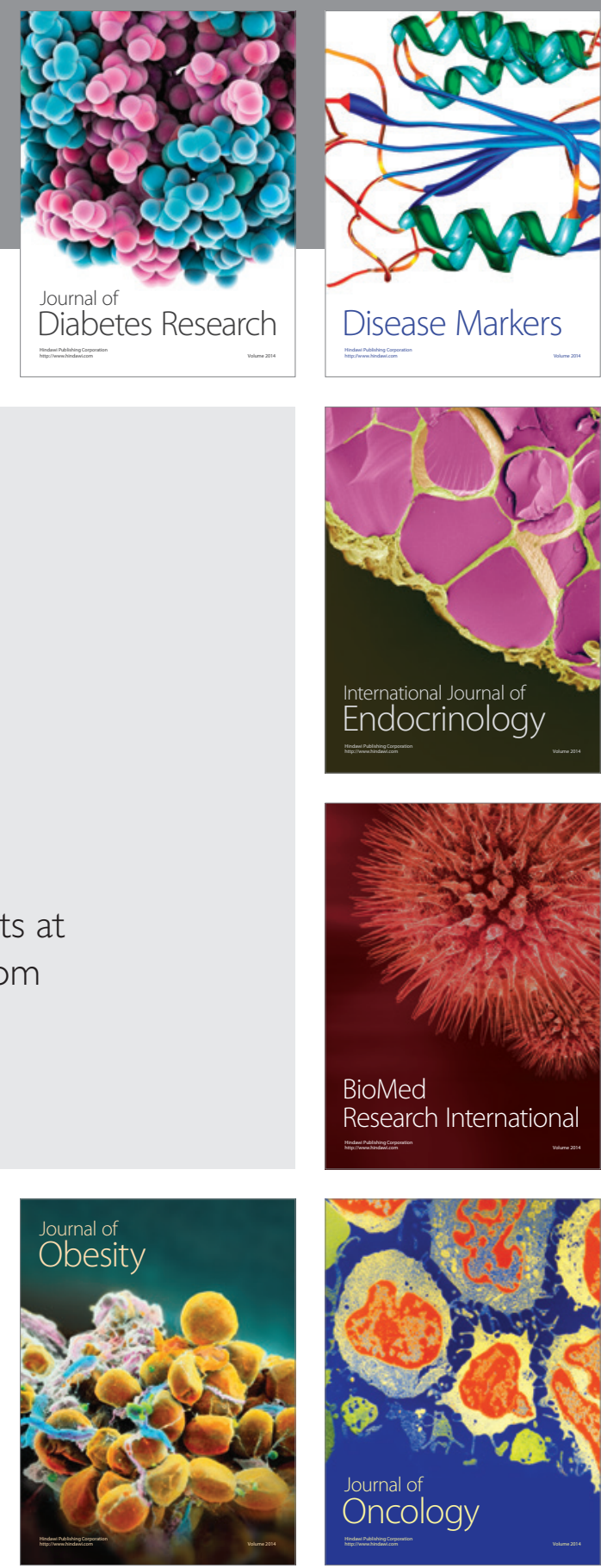

Disease Markers
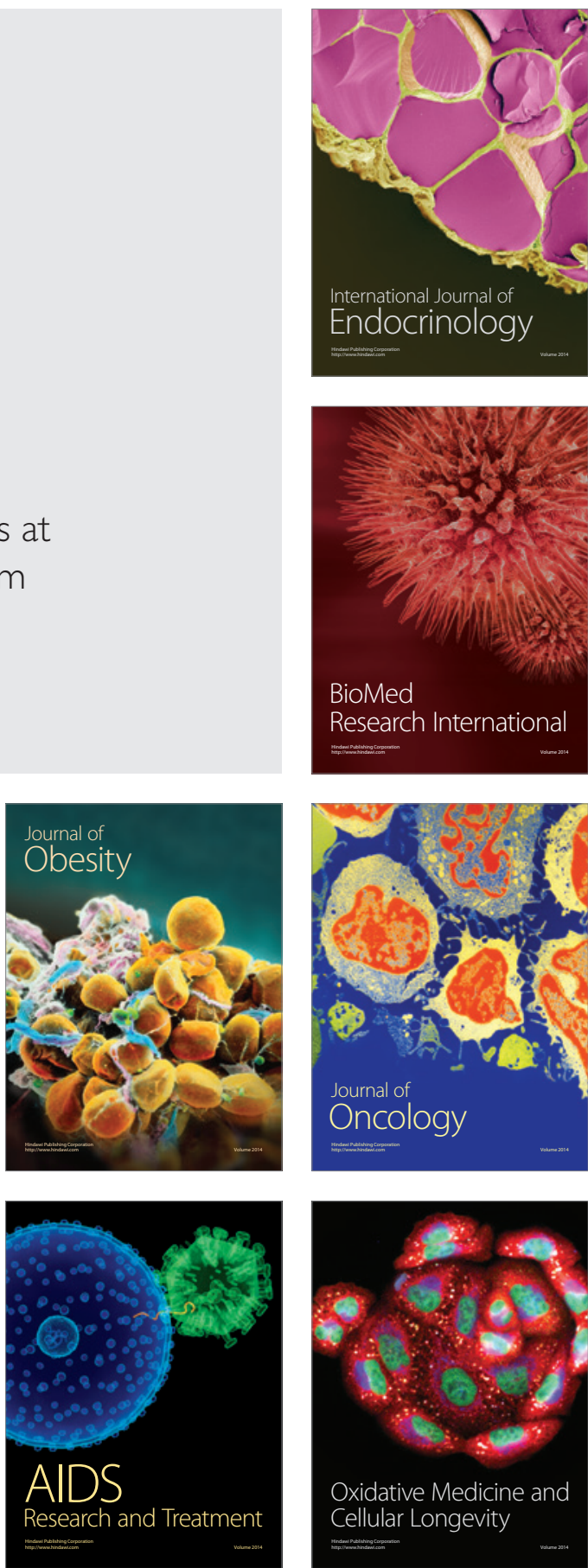